\title{
Chamber, Target and Final Focus Integrated Design
}

\author{
R. W. Moir
}

This article was submitted to $13^{\text {th }}$ International Symposium on Heavy Ion Inertial Fusion Energy, San Diego, CA, March 13-17, 2000

\section{March 3, 2000}

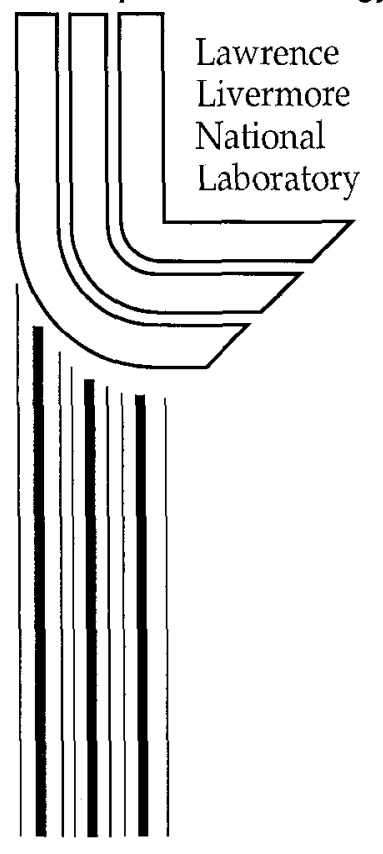





\section{DISCLAIMER}

This document was prepared as an account of work sponsored by an agency of the United States Covernment. Neither the United States Government nor the University of California nor any of their employees, makes any warranty, express or implied, or assumes any legal liability or responsibility for the accuracy, completeness, or usefulness of any information, apparatus, product, or process disclosed, or represents that its use would not infringe privately owned rights. Reference herein to any specific commercial product, process, or service by trade name, trademark, manufacturer, or otherwise, does not necessarily constitute or imply its endorsement, recommendation, or favoring by the United States Government or the University of California. The views and opinions of authors expressed herein do not necessarily state or reflect those of the United States Government or the University of California, and shall not be used for advertising or product endorsement purposes.

This is a preprint of a paper intended for publication in a journal or proceedings. Since changes may be made before publication, this preprint is made available with the understanding that it will not be cited or reproduced without the permission of the author.

This report has been reproduced

directly from the hest available copy.

Available to DOE and DOE contractors from the

Office of Scientific and Technical Information

P.O. Box 62, Oak Ridge, TN 378.31

Prices available from (423) 576-8401

http://apollo.osti.gov/bridge/

Available to the public from the

National Technical Information Service

U.S. Department of Commerce

5285 Port Royal Rd.,

Springfield, VA 22161

http://www.ntis.gov/

OR

Lawrence Livermore National Laboratory

Technical Information Department's Digital Library

http://www.llnl.gov/tid/Library.html 
Heavy Ion Fusion International Symposium, March 13-17, 2000, in San Diego, USA.

UCRL-JC-136793 abs

Chamber, target and final focus integrated design*

Ralph W. Moir

March 3, 2000

Lawrence Livermore National Laboratory, Livermore, CA, USA

Liquid wall protection, which challenges chamber clearing, has such advantages it's Heavy Ion Fusion's (HIF) main line chamber design. Thin liquid protection from $x$ rays is necessary to avoid erosion of structural surfaces and thick liquid makes structures behind $0.5 \mathrm{~m}$ of Flibe $(7$ mean free paths for $14 \mathrm{MeV}$ neutrons), last the life of the plant. Liquid wall protection holds the promise of greatly increased economic competitiveness. Driver designers require $\sim 200$ beams to illuminate recent target designs from two sides. The illumination must be compatible with liquid wall protection. The "best" values for driver energy, gain, yield and pulse rate comes out of wellknown trade-off studies. The chamber design is based on several key assumptions, which are to be proven before HIF can be shown to be feasible. The chamber R\&D needed to reduce the unknowns and risks depend on resolving a few technical issues such as jet surface smoothness and rapid chamber clearing. 
1. Introduction

2. Historical perspective

3. Chamber design

2.1 Illumination

4. Chamber clearing

4.1 Venting

4.2 Isochoric heating

4.3 Ablation

4.4 Chamber clearing of vapor by condensation on spray droplets

4.5 Positive displacement clearing, gravity clearing, gas dynamic clearing

5. Candidate liquids

5.1 Liquid lithium as a backup option to Flibe for HYLIFE-II

6. Conclusions

7. Acknowledgment

8. References

9. Figure captions 


\section{Introduction}

1. A basic consideration of plant design comes from trade-off studies with driver energy, which is one of the most important variables. At high driver energy the target gain increases which lowers the driver power and lowers the pulse rate but the most expensive part of the plant, the driver, becomes expensive. The pulse rate is adjusted to give the desired plant power. At lower driver energy the yield becomes low necessitating higher pulse rates, more pumping power, more recirculating power and more target production costs. The cost of electricity goes through a minimum as illustrated in Fig. 1 and discussed quantitatively in Ref.1. The pulse rate is often limited by how fast the chamber can be cleared ready for the next shot. In HYLIFE-I with gravity clearing of liquid lithium, the maximum pulse rate was estimated to be $1.5 \mathrm{~Hz}$. This was not at the minimum of the cost of electricity. HYLIFE-II with its much lower gain target estimates of 70 versus 400 for HYLIFE-I had a great incentive to increase the pulse rate. Positive clearing by the sweeping action of oscillating jets was invented as a way to clear the chamber fast enough for a pulse rate of $6 \mathrm{~Hz}$. This pulse rate is nearer to the minimum of cost of electricity curve. Molten salt was found to both be more economical and avoided the fire hazard of liquid lithium. The parameters of the series of HYLIFE designs are given in Table 1. 


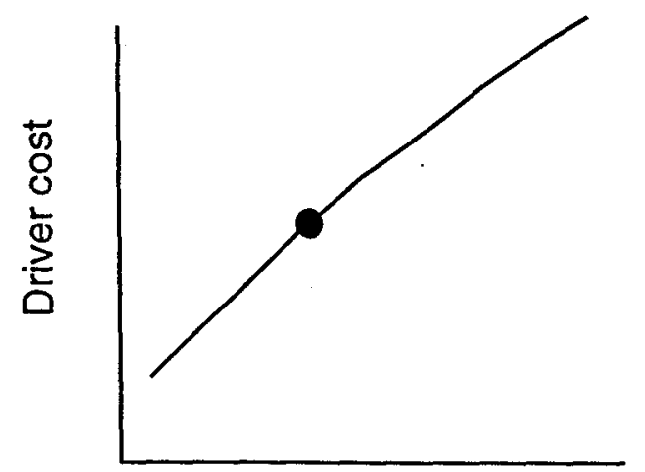

Driver energy

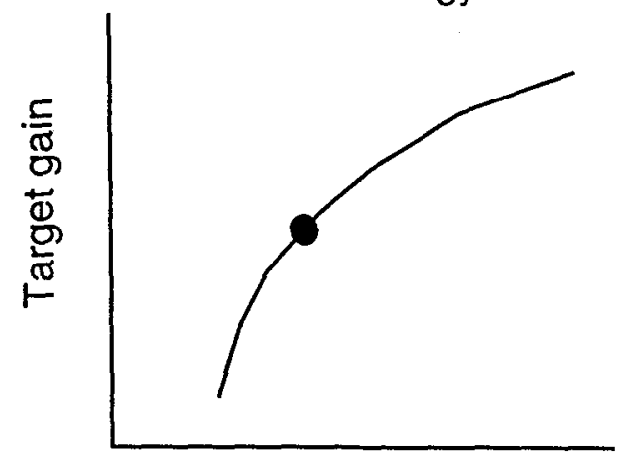

Driver energy

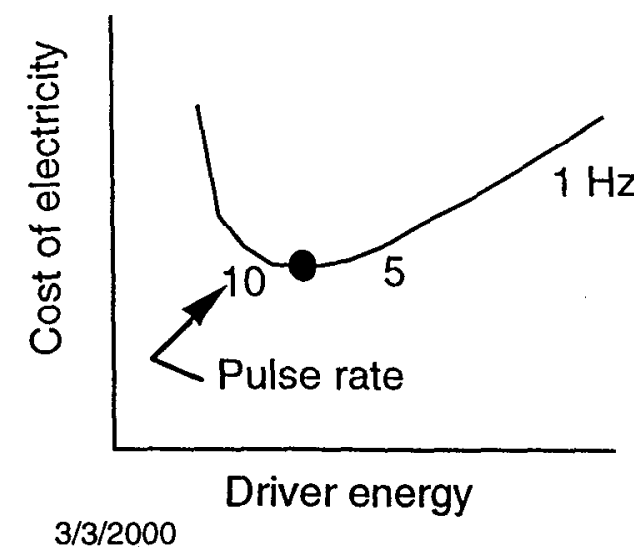

Fig. 1. The essential features resulting in $\sim 6 \mathrm{~Hz}$ pule rate from plant trade-off studies with driver energy are shown. 


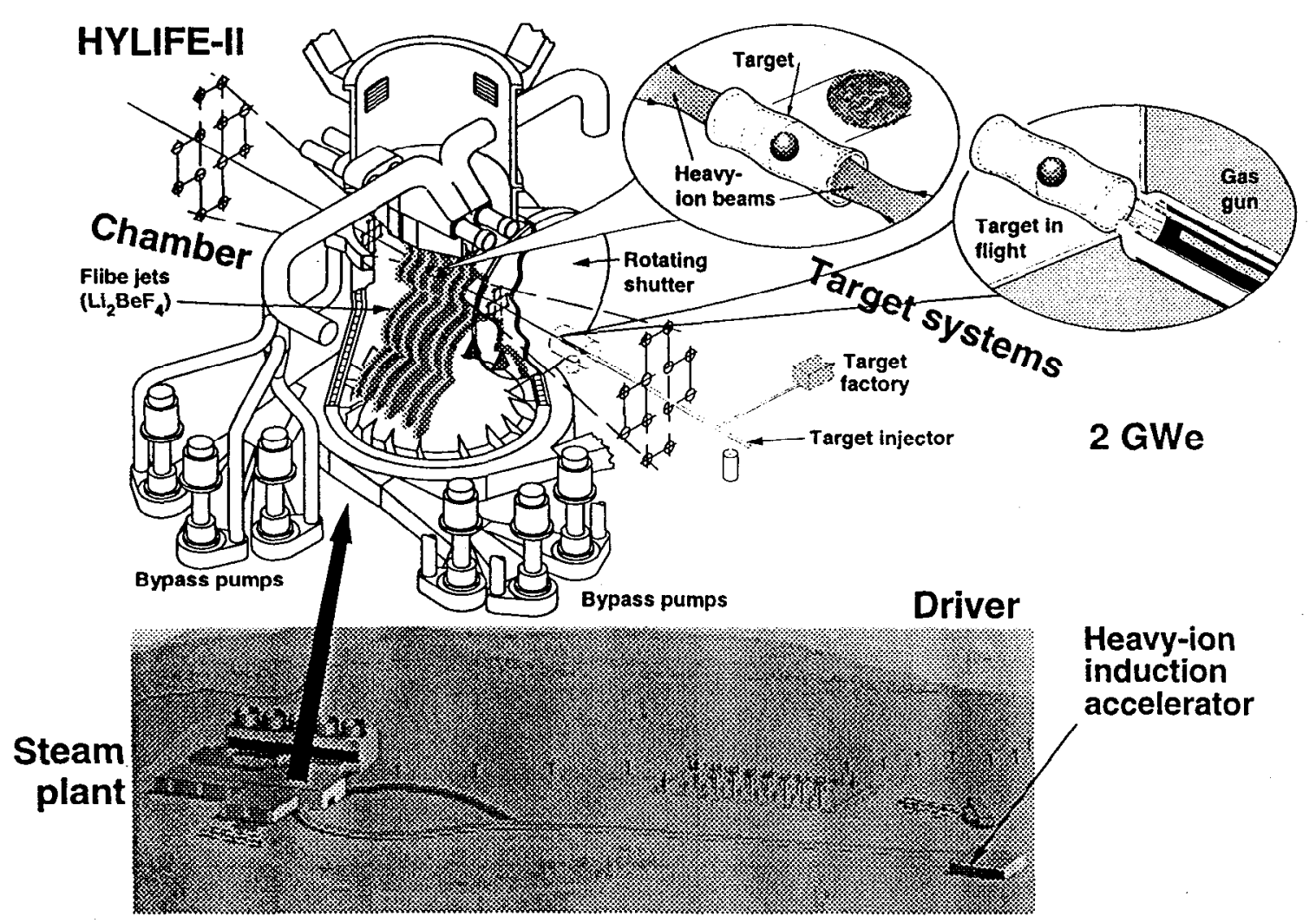

Fig. 2. Plant layout showing the driver, target and chamber. The use of liquid jets to protect the fusion chamber results in long lifetime, low cost, and low environmental impact.

\section{Historical perspective-Evolution of HYLIFE-I to HYLIFE-II.}

In the early 1970's there was a flurry of thinking on how to design fusion power plants. The ideas for a chamber design were based on the principle that liquids heal rather than accumulate damage from neutrons as is the case with structures made of metals for example. Some advantages and disadvantages of liquid walls are listed in Table 2. The impulsive forces of the microexplosions and burst of $x$ rays also pointed in the direction of using liquid walls. The design we know as HYLIFE (high-yield lithium-injection fusion energy) was conceived by Monsler et al. ${ }^{2}$ in 1978 and was based on all structures being protected by many mean free paths thickness of liquid. An extensive series of analyses of fluid dynamics and blast attenuation by liquid jets were carried out by Glenn ${ }^{3}$. His references and many refinements and design features are described in the final HYLIFE-I report by Blink et al. ${ }^{4}$ This collected works has put the HYLIFE concept on a sound fluid mechanics basis. The target gain in the old days was assumed to be 400 , which allowed a low pulse rate that permitted gravity clearing of the liquid debris and vapor. The resulting yield was the astounding number of $1800 \mathrm{MJ}$ (even higher in the earlier versions) requiring special attention to blast effects and recovery from 
violent fluid break-up due to isochoric neutron heating and other effects to be discussed in section 4 . Some characteristic parameters are given in Table 1

Table 1

Sequence of liquid wall protected chamber designs

\begin{tabular}{|c|c|c|c|c|}
\hline & HYLIFE-I & HYLIFE-II & \multicolumn{2}{|c|}{ HYLIFE-II 1999} \\
\hline $\begin{array}{l}\text { Illumination, } \\
\text { beams per side }\end{array}$ & 1 & 12 & 32 & 96 \\
\hline Liquid & Lithium & Flibe & Flibe & Flibe \\
\hline Driver & Laser & Ion & Ion & Ion \\
\hline Ed, MJ & 4.5 & 5 & 5 & 5 \\
\hline Gain & 400 & 70 & 70 & 70 \\
\hline Yield, MJ & 1800 & 350 & 350 & 350 \\
\hline Pulse rate, $\mathrm{Hz}$ & 1.5 & 6 & 6 & 6 \\
\hline Beam size, degrees & $\pm 0.9 \times \pm 2.0$ & \pm 0.9 & \pm 0.4 & \pm 0.4 \\
\hline $\begin{array}{l}\text { Beam size at } 2 \mathrm{~m} \text {, } \\
\mathrm{m}\end{array}$ & $\begin{array}{l}0.062 \times 0.14 \\
\text { rectangular }\end{array}$ & 0.062 dia & $0.28 \mathrm{dia}$ & $0.28 \mathrm{dia}$ \\
\hline $\begin{array}{l}\text { Radius to first } \\
\text { wall, } \mathrm{m}\end{array}$ & 5 & 3.0 & 3.0 & 3.0 \\
\hline $\begin{array}{l}\text { Energy/unit area at } \\
\text { first wall, } \mathrm{MJ} / \mathrm{m}^{2}\end{array}$ & $\overline{41}$ & 60 & 5.7 & 1.9 \\
\hline $\begin{array}{l}\text { Gravity fall } \\
\text { distance } \\
\mathrm{S}=0.5 \mathrm{gt}^{2}, \mathrm{~m}\end{array}$ & 2.2 & 0.14 & 0.14 & 0.14 \\
\hline $\begin{array}{l}\text { Fraction of wall } \\
\text { area taken up by } \\
\text { beams }\end{array}$ & $3.2 \times 10^{-4}$ & $7.4 \times 10^{-4}$ & $7.8 \times 10^{-4}$ & $23.4 \times 10^{-4}$ \\
\hline
\end{tabular}

*The design called for 12 beams from only one side. The target was

illuminated with 6 beams on each end from the side. When the target ${ }^{5}$ with $90^{\circ}$ bends on each end could not be designed to work on LASNEX, symmetric illumination from 2 sides with the same 12-beams layout was assumed.

Table 2

Advantages and disadvantages of liquid walls

\begin{tabular}{|c|c|}
\hline Advantages & Disadvantages \\
\hline Lower $\mathrm{COE}^{*}$ & Higher $\mathrm{COE}$ \\
\hline Higher power density/small chamber & Long chamber clearing times \\
\hline Higher availability & Costly piping and pumps \\
\hline Lower component replacement costs & Pumping power \\
\hline \multicolumn{2}{|l|}{ Higher yield is possible } \\
\hline Less activation of structures & \\
\hline Lower decay heat in structures & \\
\hline Reduced need to develop new high & \\
\hline
\end{tabular}




\begin{tabular}{|l|l|}
\hline neutron, radiation-damage materials & \\
\hline $\begin{array}{l}\text { Substitutes hydraulics unknowns for } \\
\text { radiation tolerant materials } \\
\text { development unknowns }\end{array}$ & \\
\hline
\end{tabular}

${ }^{*} \mathrm{COE}$ is cost of electricity

Starting in 1988 HYLIFE-I was reexamined and changes were made. The target performance estimates gave gains of $\sim 70$ at $\sim 5 \mathrm{MJ}$ requiring a pulse rate of about $6 \mathrm{~Hz}$. Active clearing rather than gravity clearing was necessary and the working liquid, molten salt, Flibe $\left(\mathrm{LiF}+\mathrm{BeF}_{2}\right)$ was adopted. In 1991, the HYLIFE-II design had taken its essential form it has today and integrated target, chamber and driver designs were strongly called for and an early paper on integration ${ }^{6}$ was written. Detailed modeling of chamber phenomena was begun to aid chamber design and help predict performance, especially chamber clearing time. The effort on chamber design and chamber phenomena modeling were virtually stopped in 1991 and documented in Ref. 7 with a summary of the entire design study published in 1994, Ref. 8. It is strongly recommended to restart a vigorous design and modeling effort on liquid-walled chambers and phenomena to arrive at an integrated design selfconsistent with the target and driver.

\section{A no leakage beam port protection concept}

The small fraction of uncollided neutrons (see Table 1) passes up the beam lines produces activation of the surrounding material. This activation could be further reduced if even these neutrons were attenuated. This may be possible by aiming the beams somewhat away from directly at the capsule inside the target and channeling the radiation to the capsule "around a corner." The idea of shielding even the beam line was discussed in Ref. 9, where it was argued; it might be possible to provide $0.3 \mathrm{~m}$ of shielding. This would give up to 4 mean free paths of attenuation for neutrons headed exactly up the beam lines at $0.07 \mathrm{~m}$ for a mean free path for $14 \mathrm{MeV}$ neutrons. This would help reduce the radiological impact of the plant. The use of liquid walls is a step in the direction of making the design look "non-nuclear." Eliminating uncollided neutrons from streaming up the beam ports is yet another step in the direction of "non-nuclear." Another way to accomplish the same end would be to use a magnetic field in the chamber to bend the ion beam so that the target is out of line of sight of the beam ports. Activation especially up the beam lines is discussed in Ref.10.

\section{Chamber design}

There are two high-level chamber design questions on our minds: Will chamber clearing work for pulse rates $\sim 6 \mathrm{~Hz}$ ? And will the idea of liquid wall protection be able to accommodate the direction the ion driver designs are 
heading, namely a large number of beams, presently 96 beams per side? Chamber clearing will be discussed in the section following this one. The number of beams started at 12 per side but this design resulted in too expensive electricity from a market point of view due to the costly driver (10 $\mathrm{GeV}, \mathrm{Pb}^{+}$ions). Next 32 beams per side ( $6 \times 6$ array with the four corners left off) were studied and then we jumped to 96 per side $(10 \times 10$ array with the four corners left off). The reason to go to a larger number of beams is a direct result of the attempt to reduce the cost of the driver. The $10 \mathrm{GeV}$ mass 200 $\left(\mathrm{Pb}^{+}\right.$for example) driver at an average voltage gradient of $1 \mathrm{MW} / \mathrm{m}$ was 10 $\mathrm{km}$ long and cost nearly $2 \mathrm{~B} \$$ direct cost. From a space charge point of view and other considerations it was thought that the $5 \mathrm{MJ}$ energy, which was required by the target, could be delivered in $~ 10$ beams at least after the low energy early part of the accelerator. There were at least four strategies to lower the cost: 1-recirculate the beam through the same accelerator many time, 2lower the ion energy and mass so as to shorten the accelerator, 3-increase the gradient to also shorten the accelerator and, 4-use charge state two or three ions for driver cost reduction. The goal has been to get the direct cost down to about $500 \mathrm{M} \$$. So the ongoing effort is now to see if 96 beams per side, 192 total will work with ions more like ${ }^{85} \mathrm{Rb}^{+}$at $1.44 \mathrm{GeV}$. This accelerator might be only $1.4 \mathrm{~km}$ long. The target ${ }^{11}$ at present calls for beams within a cone angle of $\pm 12^{\circ}$ whereas the beams shown as a square array in Fig. 3 is a cone of $\pm 22.4^{\circ}$.

House ${ }^{12,13}$ describes the chamber and liquid jets especially for beam port protection for the 96-beam-per-side case, which are shown in the Figs. 2 to 5. The series of drawings illustrates the need for liquid jets of unusually good surface quality or surface roughness so they can be close fitting to the ion beam paths and still provide $0.5 \mathrm{~m}$ or 7 mean free paths of shielding of the beam ports. The surface roughness assumed is measured by the height of the surface ripples above the smooth jet for a given distance away from the jet's nozzle. The vertical jets call for a ripple height of $9 \mathrm{~mm}$ in a distance of $1.61 \mathrm{~m}$ or $5.6 \mathrm{~mm} / \mathrm{m}$ or an angle of spread of 0.0056 radians or 0.3 degrees. The horizontal jets call for a ripple height of $4 \mathrm{~mm}$ in a distance of $2.26 \mathrm{~m}$ or 1.8 $\mathrm{mm} / \mathrm{m}$ or an angle of spread of 0.0018 radians or 0.1 degrees. A high priority is to see just how smooth jets can be made and also to see if the design can accommodate jets with larger ripples. Relevant jet research is ongoing at UC Berkeley ${ }^{14}$, Georgia Institute of Technology ${ }^{15}$ and UCLA ${ }^{16}$. 


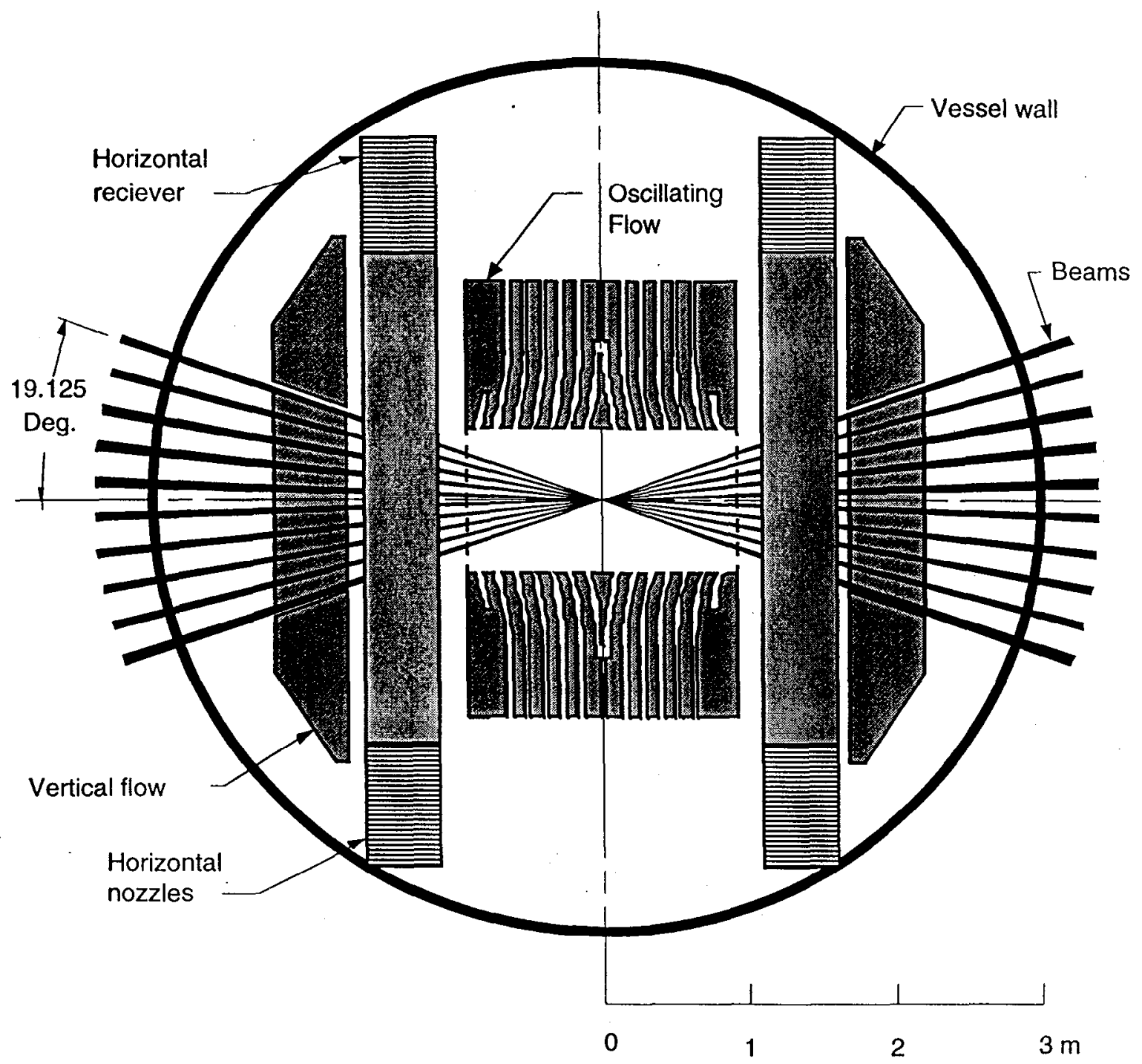

Fig. 3. Chamber plan view. Note that liquid protects all the walls except up the beam lines. Venting can take place through the slots in the oscillating jets and around the jets. The circular cone encompassing the $19.1^{\circ}$ square array of beams is $\pm 22.4^{\circ}$. 


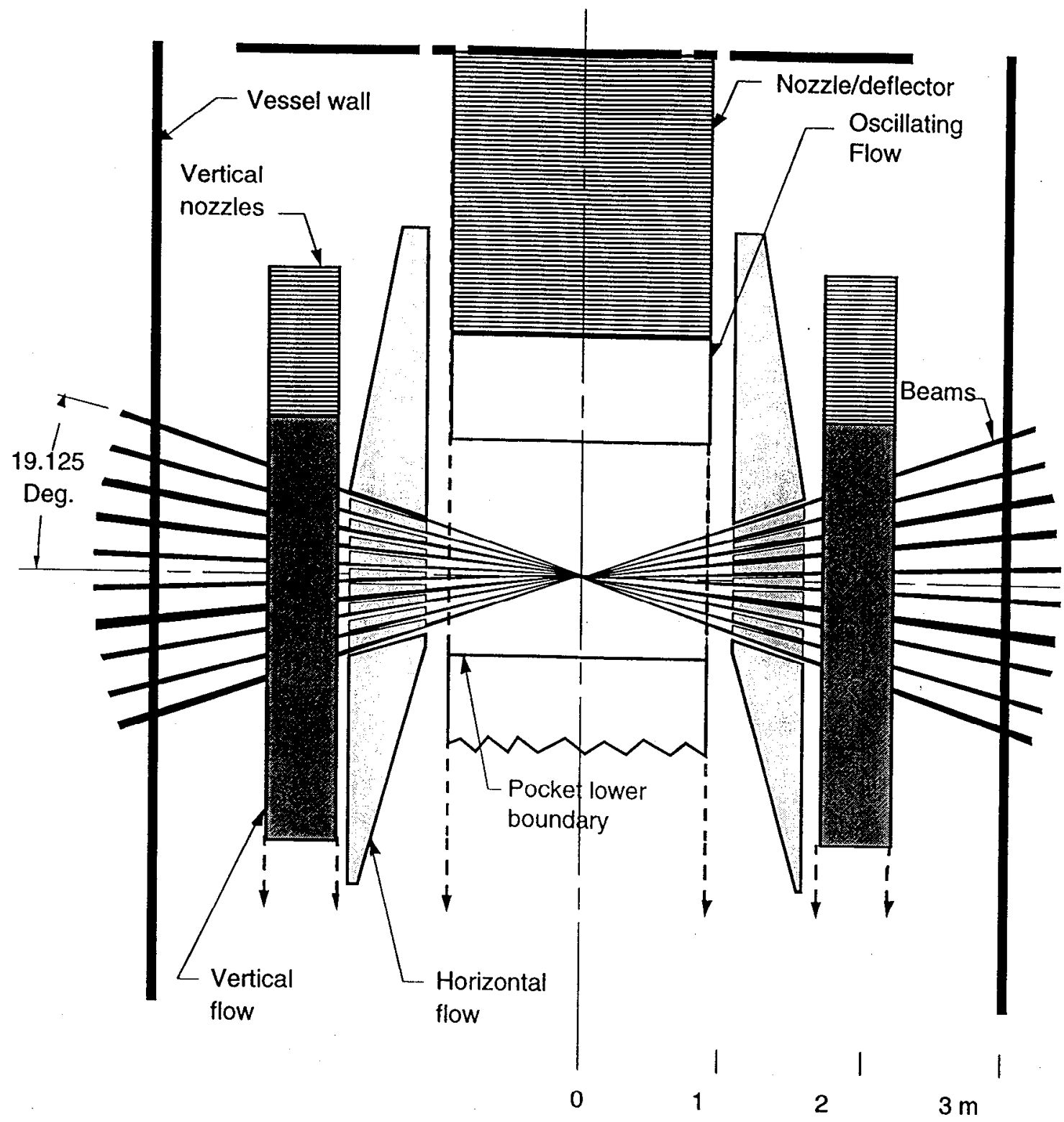

Fig. 4. Chamber, side view. 


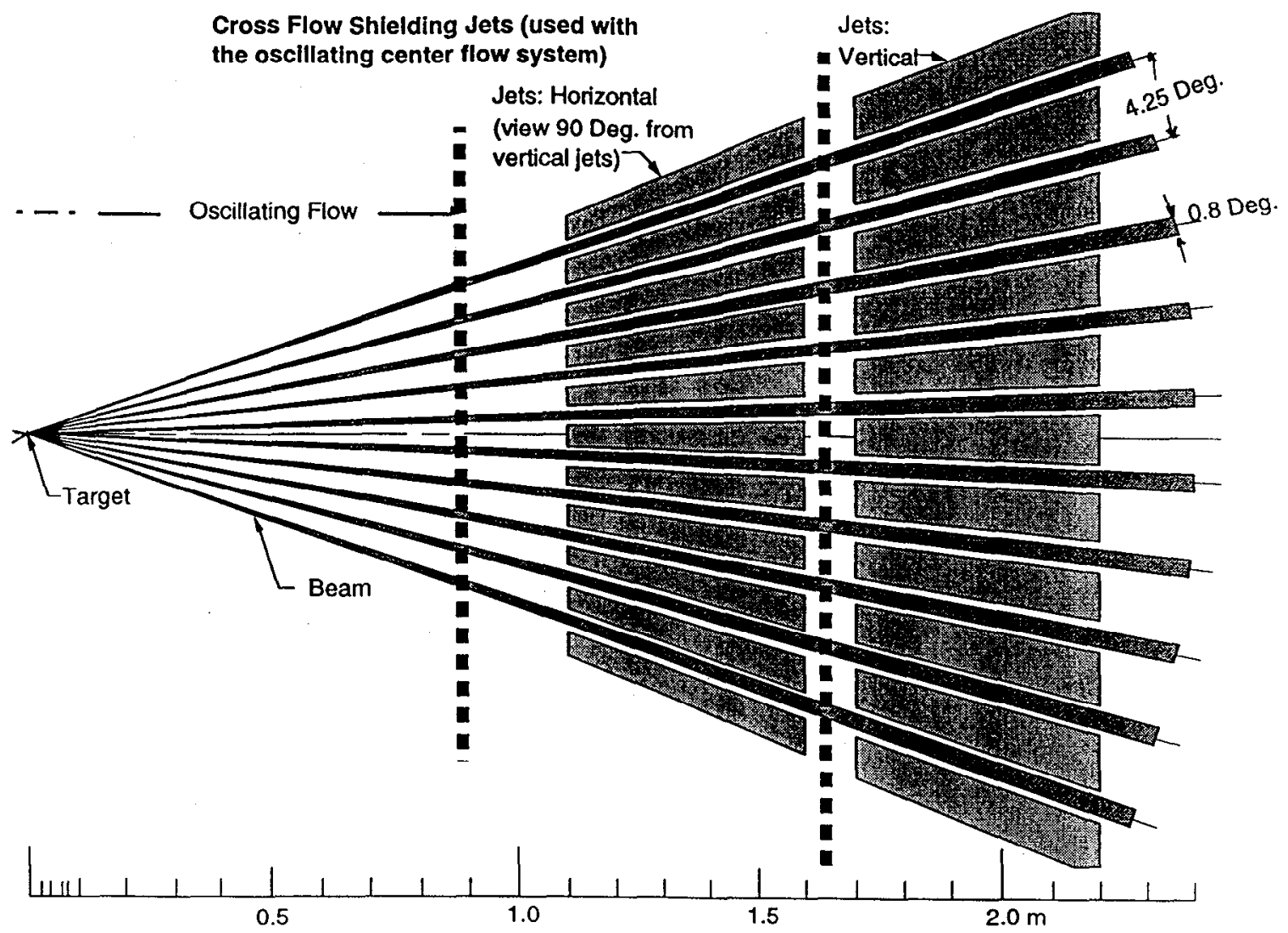

Fig. 5. Cross flow shielding jets, which protect the beam ports. 


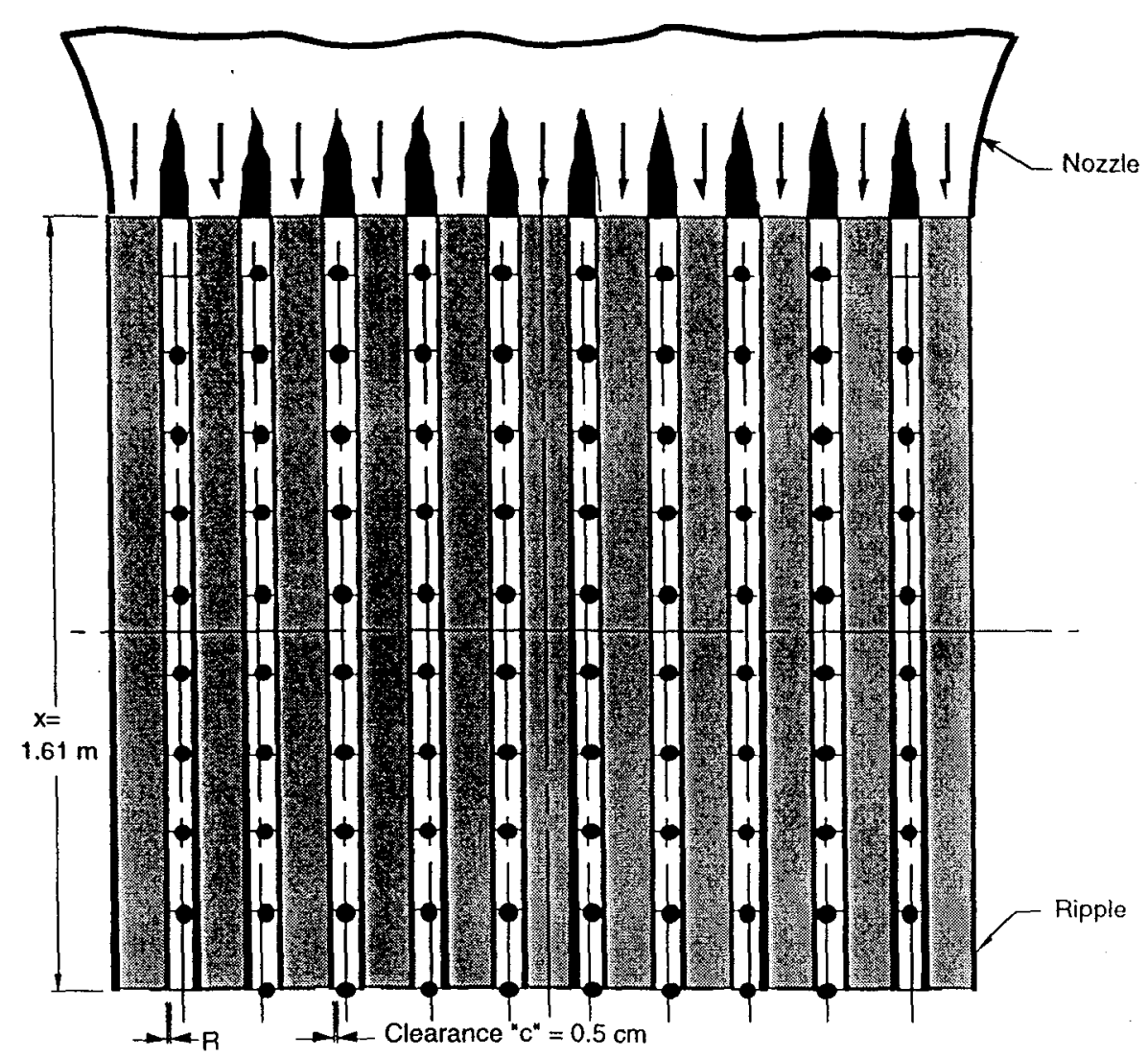

$\mathrm{R}=\mathrm{ax}=(0.0056)(1.61)=.009 \mathrm{~m},(0.9 \mathrm{~cm})$. $(\mathrm{a}=0.0056 \mathrm{~m} / \mathrm{m})$

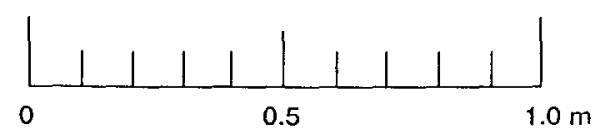

Fig. 6. Vertical jets for beam port protection.

The important parameters impacting beam port protection designs are the beam size (cone of $\pm 0.4^{\circ}$ ) and the spacing between beams (4.25 see Fig. 5).

Note in Fig. 6 that the manifold that delivers the liquid to the jets has a restricted amount of space for structure. The convergence ratio of the manifold to jets is only about 1.6 to 1 . The design calls for placing a close fitting liquid vortex around each beam to "clip" the neutrons steaming up the beam line in a roughly square cross section shadowed by the cross jets shown in Figs. 2 to 5. These vortexes are discussed in Ref. 12.

While it is too early in the design iteration process to assume jets of the required smoothness as shown in the prior figures will be realized, it would appear to be prudent to evolve the design to permit a larger space between the ion beams and the surface of the liquid jets. A smaller number of beams than a 10x10 array such as a $9 \times 9$ array could be considered and a larger spacing between beams than the $4.25^{\circ}$ shown in Fig. 5 could be studied. 


\section{Chamber clearing}

The subject of chamber clearing was of much interest in the early part of the HYLIFE-II design study. This follows because the primary difference between HYLIFE-I and II was going from $1.5 \mathrm{~Hz}$ where gravity clearing was thought to work to having to go to $6 \mathrm{~Hz}$ due to the lower yields coming from the targets that were in style about 1991. This high of pulse rate allowed little or no time for gravity clearing of liquid debris and therefore necessitated an active clearing method. The 1991 report $^{7}$ by many authors called the "Green book" contains a discussion, which will be summarized here on chamber clearing phenomena.

\subsection{Venting}

The $x$ rays and debris from the target produce a vapor build up in the liquid pocket region. This vapor vents through the spaces shown in Figs. 3 and 4 . The vapor must be pumped away for the next shot, which is the subject of section 4.4. During venting, the liquid jets are accelerated by the pressure of the vapor on the interior surfaces.

$$
\begin{aligned}
& v=\frac{\int P d t}{\text { mass / area }}=\frac{\text { impulse / area }}{\text { mass } / \text { area }}=\frac{\text { mass } \times \text { velocity / area }}{\text { mass / area }}=P_{0} \tau / \rho \Delta r \\
& P_{0}=\frac{(\gamma-1) E}{V}=\frac{(1.2-1) \times(105 \mathrm{MJ}-7.3 \times 5)}{2.1 \mathrm{~m}^{3}}=6.5 \mathrm{MPa}
\end{aligned}
$$

The latter term in parentheses accounts for the energy to heat up the Flibe to the vaporization temperature and the heat of vaporization. For an average thickness of $0.5 \mathrm{~m}$ and a spacing of $5 \mathrm{~cm}$ gap and $7 \mathrm{~cm}$ jet thickness a radial thickness of the jets would be $0.5 \times 12 / 7=0.857 \mathrm{~m}$.

$$
\begin{aligned}
& \rho \Delta r=2050 \mathrm{~kg} / \mathrm{m}^{3} \times 1 \mathrm{~m}=2050 \mathrm{~kg} / \mathrm{m}^{2} \\
& \tau=\frac{V}{C A_{1}} ; \quad \mathrm{A}_{1}=\eta \mathrm{A}_{0} ; \eta=\text { void fraction }
\end{aligned}
$$

Where the inner area, $A_{0}$, is $8.7 \mathrm{~m}^{2}$, the void fraction is $5 / 12=0.417 \mathrm{~m}$ $\mathrm{C}=$ sound speed $=(\gamma \mathrm{RT} / \mathrm{M})^{1 / 2}=1230 \mathrm{~m} / \mathrm{s}$ at $5000 \mathrm{~K} ; \mathrm{M}=33$ for an average of dissociated molecules.

$$
\tau=\frac{2.1 \mathrm{~m}^{3}}{1230 \mathrm{~m} / \mathrm{s} \times 8.7 \mathrm{~m}^{2} \times 0.417}=0.47 \mathrm{~ms}
$$

The void fraction for $70 \mathrm{~mm}$ wide jets with $50 \mathrm{~mm}$ spacing is $50 / 120=0.417$. 
$v=\frac{6.5 \mathrm{MPa} \times 0.47 \mathrm{~ms}}{2050 \mathrm{~kg} / \mathrm{m}^{2}}=1.5 \mathrm{~m} / \mathrm{s}$

This is the average outward speed of the liquid is $1.5 \mathrm{~m} / \mathrm{s}$.

The scaling of velocity;

$\mathrm{v} \propto \mathrm{E}(1-\eta) /\left(\mathrm{A}_{\mathrm{o}} \eta \rho\right)$

$v \propto \frac{E}{\eta r^{2} \rho \Delta r} \propto \frac{(1-\eta)}{\eta} \frac{E}{r^{2}}$

If the void space used for venting (void fraction, $\eta$ ) becomes restricted then the liquid will get accelerated more during the longer time venting takes place. Its also important to maintain a good standoff distance to the liquid, $r$ ( $r=0.5 \mathrm{~m}$ in our reference design).

\subsection{Isochoric heating}

The isochoric heating of the liquid jets causes them to develop a large internal pressure. This pressure is relieved by expansion and by breakup of the jets. The net outward velocity is given by Glenn ${ }^{3}$ including the factor of 0.3 from his studies of internal dissipation due to jet breakup self-collisions.

$v=\frac{\Gamma E}{C m}(0.3)$

$\Gamma=$ Gruniesen parameter $=1.02$ for Flibe

$\mathrm{E}=0.7 \times 350 \mathrm{MJ}=245 \mathrm{MJ}$

$C=$ speed of sound in Flibe $=3250 \mathrm{~m} / \mathrm{s}$

$\mathrm{m}=13,950 \mathrm{~kg}$

$\eta=$ void fraction $=0.417$

$\mathrm{v}=1.7 \mathrm{~m} / \mathrm{s}$

Some of the liquid will have higher speed than the average. The liquid velocity due to isochoric heating scales as:

$v \propto \frac{E}{r^{2} \rho} \propto \frac{E}{r^{2} \rho \Delta r(1-\eta)}$

Again we see it is important to maintain a minimum standoff distance, $r$, to the liquid jets from the target. 


\subsection{Ablation}

During the ablation process, the liquid jets are accelerated due to the rocket action of ablation.

From conservation of momentum we get:

$\mathrm{m}_{\text {vapor }} \mathrm{v}_{\text {vapor }}=\mathrm{m}_{\text {liquid }} \mathrm{v}_{\text {liquid }}$

The energy in the vapor, $\mathrm{E}_{\mathrm{vapor}}$ is:

$\mathrm{E}_{\text {vapor }}=1 / 2 \mathrm{~m}_{\text {vapor }} \mathrm{v}_{\text {vapor }}{ }^{2}$

$v_{\text {liquid }}=\frac{\left(2 m_{\text {vapor }} E_{\text {vapor }}\right)^{1 / 2} / \text { area }}{m_{\text {liquid }} / \text { area }}$

The pocket area is estimated at $8.7 \mathrm{~m}^{2}(7 \mathrm{~cm}$ wide jets are spaced every $12 \mathrm{~cm})$ giving an interior area of liquid of $5.0 \mathrm{~m}^{2}$. In Ref. $7 \mathrm{p} 4-4$ the amount of material evaporated is estimated at $40 \mu \mathrm{m}$, so the evaporated mass is estimated to be:

$\mathrm{m}_{\text {vapor }}=40 \mu \mathrm{m} \times 5.07 \mathrm{~m}^{2} 2050 \mathrm{~kg} / \mathrm{m}^{3}=0.4 \mathrm{~kg}$

$\mathrm{E}_{\mathrm{vapor}}=0.3$ Yield $=0.3 \times 350 \mathrm{MJ}=105 \mathrm{MJ}$

$v_{\text {liquid }}=\frac{(2 \times 0.4 \mathrm{~kg} \times 105 \mathrm{MJ})^{1 / 2} / 5.1 \mathrm{~m}^{2}}{1760 \mathrm{~kg} / \mathrm{m}^{2}}=1.0 \mathrm{~m} / \mathrm{s}$

The speed the jets are accelerated to scales as

$$
\begin{aligned}
& m_{\text {vapor }} \propto(1-\eta) \mathrm{A}_{\mathrm{o}} E^{1 / 2} \\
& v \propto \frac{(1-\eta)^{1 / 2} E^{3 / 4}}{\mathrm{~A}_{\mathrm{o}}^{1 / 2}} \\
& v \propto \frac{(1-\eta)^{1 / 2} E^{3 / 4}}{r \rho} \propto \frac{E^{3 / 4}}{(1-\eta)^{1 / 2} r \rho \Delta r}
\end{aligned}
$$

Table 3

Summary of chamber scaling 


\begin{tabular}{|l|c|c|}
\hline Process & Liquid speed & Scaling \\
\hline Venting & $1.5 \mathrm{~m} / \mathrm{s}$ & $v \propto \frac{E}{\eta r^{2} \rho \Delta r}$ \\
\hline Ablation & $1.0 \mathrm{~m} / \mathrm{s}$ & $v \propto \frac{E^{3 / 4}}{(1-\eta)^{1 / 2} r \rho \Delta r}$ \\
\hline $\begin{array}{l}\text { Isochoric } \\
\text { heating }\end{array}$ & $1.7 \mathrm{~m} / \mathrm{s}$ & $v \propto \frac{E}{(1-\eta) r^{2} \rho \Delta r}$ \\
\hline Total & $4.2 \mathrm{~m} / \mathrm{s}$ & \\
\hline
\end{tabular}

There is a word of caution! While the average liquid is accelerated to $4.2 \mathrm{~m} / \mathrm{s}$ the inner layer is accelerated too much higher speeds which might not become fully averaged out. The danger is high-speed "chunks" of liquid hitting the walls will cause damage due to over stressing. The downward speed is nominally $12 \mathrm{~m} / \mathrm{s}$ so the average liquid will not hit the sidewalls until the lower region of the chamber where the walls are tapered to minimize the impact stresses. A "curtain" of slow moving liquid can be placed near the wall to intercept small amounts of high-speed chunks of liquid. Also, the walls would be coated with slow flowing liquid for erosion protection and to protect the walls from dissociated vapor which would cause corrosion.

\subsection{Chamber clearing of vapor by condensation on spray droplets}

Within a millisecond or so after each shot the evaporated material will come to equilibrium and then begin to be pumped. Actually it is more complicated with reverberating shock waves and radiation evaporating more material but essentially the rapid dynamics more or less settle down to an equilibrium state of vapor filling the entire chamber. In HYLIFE-I the assumption was the venting vapor would break up the liquid jets into small droplets onto which the cloud would condense. In HYLIFE-II a more conservative assumption was adopted where adequate droplet spray was injected into the chamber so that in a deterministic and predictable way the condensation was to take place. This assumption might be overly conservative. See Ref.8 p17 for details.

We assume a typical shot of $350 \mathrm{MJ}$ produces about $100 \mathrm{MJ}$ of $x$ rays and debris which after shock waves settle down and re-radiation and evaporation takes place about $14 \mathrm{~kg}$ of Flibe is evaporated forming the cloud. Dissociated molecules recombine fast enough; $\mathrm{Li}+\mathrm{F} \rightarrow->\mathrm{LiF} ; \mathrm{Be}+\mathrm{F}+\mathrm{F}-->\mathrm{BeF}_{2}$ etc.

Calculations say this occurs fast enough in the volume (homogeneous recombination) so as not to retard condensation; however, surface (heterogeneous recombination) will occur even faster. Target debris mass is 
insignificant compared to evaporated Flibe mass; $30 \mathrm{wtppm}$ high $\mathrm{Z}$ material, 0.3 wtppm for DT; 0.01 wtppm $O$ and $C ; 2$ wtppm capsule material (Be or Li or polystyrene or what ever the capsule is made of). The spray must remove 100 MJ of energy by heating up droplets. The heat flows to the center of droplets slowly therefore we use small droplets of $2-\mathrm{mm}$ dia and enough of them to remove this $100 \mathrm{MJ}$ in 1/6 of a second. The time history is shown in Fig. 6 . We assume we need 210 spray heads $100 \mathrm{~mm}$ in diameter with seventeen hundred 1-mm dia holes in each head for a flow rate of $2400 \mathrm{~kg} / \mathrm{s}$ of Flibe. The spry is directed such that the average length of drop trajectories is $1 \mathrm{~m}$ so the "old" droplets do not become an excessive evaporation source. We provide enough surface area of droplets so that arrival is not limiting (nvA/4; this is satisfied by a factor of 100). Apparently spray condensation pumping can overwhelm the pumping process and is predictable. The subject of condensation pumping has been studied in Ref. 17. The early phase of gas dynamics and jetting of gas up the beam lines has been studied in Ref. 18, where the amount of material passing the ports at $3 \mathrm{~m}$ in the wall on each shot is estimated at $3.6 \times 10^{-3} \mathrm{~g} / \mathrm{cm}^{2}$. The equilibrium vapor density including injection of specially placed cooler jets is being studied my Molvik ${ }^{19}$.

Experiments are needed to validate and help develop predictive models for condensation.

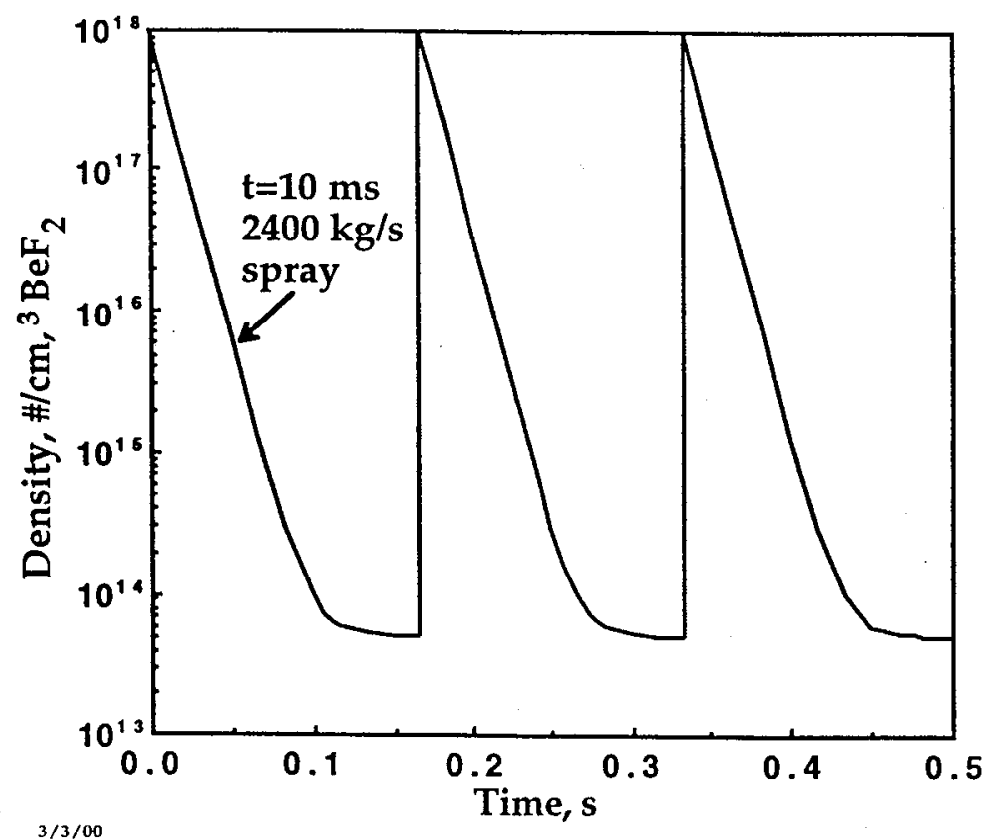

Fig. 7. Density versus time showing condensation pumping and equilibrium vapor density.

\subsection{Positive displacement clearing, gravity clearing, gas dynamic clearing}

In HYLIFE-I gravity was assumed to clear the chamber of liquid debris in a time of $1.5 \mathrm{~Hz}$. The average isochoric heating break up outward speed of the 
liquid was over $50 \mathrm{~m} / \mathrm{s}$. Clearly the chamber would be filled with lots of splashed debris. In $0.67 \mathrm{~s}$ the fall distance is $2.2 \mathrm{~m}$. If the initial speed is upward then the fall distance is only $1 / 4$ of this. Gravity clearing was adequate for the beam lines but marginal at best for the chamber.

In HYLIFE-II with $6 \mathrm{~Hz}$ pulse rate gravity clearing is completely inadequate for the chamber and possible but marginal for the beam lines. Liquid jets were located directly above and below the beams so as to make the distance for gravity to clear debris short enough. In the chamber the concept of positive displacement was employed like a piston sweeping through the region to clear debris. Oscillating liquid jets served this positive displacement-clearing role. An alternative or backup option was to pulse liquid jets on and off. The leading edge would sweep the chamber clear and the trailing edge would form the cavity or pocket.

Another clearing method mentioned in the Osiris report ${ }^{20}$, called gas dynamic clearing. The rapidly venting vapor can carry with it liquid debris and give it a significant outward speed by drag. This clearing method has not be studied much and in fact is worrisome in that this "wind" can tear droplets from the surface and send them up the beam lines where they may not be removed either by gravity or by shutters and interfere with the next beam shot. This concern needs to be further looked into.

\subsection{Summary of chamber clearing and design evolution.}

Clearing the chamber for the next shot at high pulse rates of $\sim 6 \mathrm{~Hz}$ is based on design principles and fluid dynamics that are well known as isolated phenomenon. When all processes are taken together we can not be sure chamber clearing will be adequate and experiments are essential to raise the level of confidence to proceed to the next step in development, such as an Integrated Research Experiment (IRE). The design evolution will be strongly effected by the outcome of experiments.

\section{Candidate liquids}

The question of why Flibe was chosen for HYLIFE-II keeps coming up with its nastiness of beryllium and fluorine to deal with. There were a number of reasons, which have been discussed elsewhere. Two will be mentioned: 1avoid its water and air fire of liquid lithium and, 2- Flibe was strongly preferred from the point of view of pumping power.

The power required to pump the liquid can become substantial. In Ref. 21. Several liquids are compared for use in a HYLIFE-II type geometry. It is found that dense liquids with a longer neutron mean free path have higher pumping power than short mean free path liquids. The pumping power is 
roughly proportional to $\rho \mathrm{f}^{3}(\Delta R)^{4.5}$, where $\mathrm{f}$ is the pulse rate $\Delta R$ is the liquid thickness needed to protect the structures from damage and $\rho$ is the density of the candidate liquid ${ }^{22}$. Based on this relationship and estimates of $\Delta R$ we found lithium is favored at low pulse rates, and Flibe at high pulse rates with significant pumping power penalties for the tin-lithium mixture, and even more so for lead-lithium. There are many factors in selection of a candidate liquid, as the example in the next section will illustrate in a case study of lithium.

\subsection{Liquid lithium as a backup option to Flibe for HYLIFE-II}

If for some reason Flibe proves undesirable or unworkable, liquid lithium could be used for HYLIFE-II as it was in HYLIFE-I. There are a number of design changes that would be needed and the cost of electricity would go up. Safety is one of the primary reasons to use Flibe; however, lower cost of electricity is another strong reason. This note describes these changes in a very preliminary way.

The jet thickness total would go from $0.5 \mathrm{~m}$ to $1.6 \mathrm{~m}$ in order to stop neutrons enough to protect the structural walls $(\sim 7$ mean free paths for neutrons). The operating temperature of $650^{\circ} \mathrm{C}$ (maximum primary loop temperature) would have to be lowered to $520^{\circ} \mathrm{C}$ to keep the same vapor pressure for beam propagation. The compatibility with steels also requires this lower temperature but refractory metals like vanadium alloys can at considerable cost permit higher temperature with lithium if beam propagation can work in the higher pressures.

Tritium retention in liquid lithium is so good that the vapor pressure of tritium would be very low and the vacuum disengagers would not be needed, but rather replaced by a different tritium extraction system. One such system is molten salt contact extraction followed by electrolysis. Another tritium recovery method is cold trapping to precipitate LiT. The question of an intermediate coolant versus a double walled heat exchanger to mitigate water/lithium fires would be up to design and analysis. Fire suppression systems would be needed. These changes were not includes.

A modified cost estimate is shown in Table 4. The steam system could not be super-critical. The steam plant efficiency might be somewhat less dropping from $43 \%$ to $41 \%$. There is more lithium through put because lithium has a four times lower density than Flibe and thus requires putting lithium at a greater radial distance giving more area by radius squared for a linear necessary increase in the radial thickness of lithium. To attenuate neutrons to protect the nozzle tips a higher speed of injection of $15 \mathrm{~m} / \mathrm{s}$ up from $12 \mathrm{~m} / \mathrm{s}$ was required for $6 \mathrm{~Hz}$ operation. The flow rate goes from $31 \mathrm{~m}^{3} / \mathrm{s}$ in the nozzles to $226 \mathrm{~m}^{3} / \mathrm{s}$ and the mass flow rate approximately doubles. A 6-m 
radius chamber is needed. The cost scales as the radius to the 1.7 power. We assume the material cost the same as 304 SS. If Vanadium alloy is used the cost would go up considerably. For HT-9 the cost might drop somewhat. The cost of electricity changes from $4.4 \propto / \mathrm{kWh}$ for Flibe to $5.2 \propto / \mathrm{kWh}$ for liquid lithium. Each change was applied incrementally without optimizing the plant parameters. Also it may be possible to make a liquid lithium design where the changes are less negative than used here.

The point of showing this example is to show there are many trade-offs in arriving at a design and in the case of HYLIFE-II the choice of Flibe relative to other possible liquids has not been exhaustively studied but the advantages of Flibe appear to be quite large. It would be worthwhile for independent studies to reexamine all aspects of the HYILIFE-II design.

Table 4

Cost of electricity for Li replacing Flibe in HYLIFE-II

\begin{tabular}{|l|l|}
\hline Cost of electricity for Flibe & $4.4 \not / \mathrm{kWh}$ \\
\hline Changes for $\mathrm{Li}$ & \\
\hline$\eta_{\mathrm{Th}} \quad 43 \% \rightarrow 41 \%$ & $5.0 \%$ \\
\hline Pumping power 32 MWe to $64 \mathrm{MWe}$ & $3.2 \%$ \\
\hline Chamber cost 32M $\$$ to $98 \mathrm{M} \$$ & $4.4 \%$ \\
\hline Bypass pumps 61 $\mathrm{M} \$$ to $120 \mathrm{M} \$$ & $3.9 \%$ \\
\hline Bypass piping 10 $\mathrm{M} \$$ to $20 \mathrm{M} \$$ & $0.7 \%$ \\
\hline Total change & $17.2 \%$ \\
\hline Cost of electricity for $\mathrm{Li}$ & $5.2 \not / \mathrm{kWh}$ \\
\hline
\end{tabular}

\section{Conclusions}

Enough is known about the design of the target, ion driver and especially its final focus and transport system, and the chamber that an integrated and detailed design can be carried out. This paper discusses some of the topics of importance to an integrated design. The design in its present state either appears feasible with an uneconomically too high of energy and therefore too costly driver or appears unworkable with the lower energy but lower cost driver. The invention process is far from over and this activity can be expected to generate new solutions and guide laboratory research. The principle of protecting all structures by many mean free paths $(\sim 7)$ of liquid to avoid many risky and costly development steps with solid first walls is strongly recommended. Special effects experimentation and integrated experiments are needed. 


\section{Acknowledgments}

This work was performed under the auspices of the U.S. Department of Energy by University of California Lawrence Livermore National Laboratory under contract No. W-7405-Eng-48.

\section{References}

[1] R. W. Moir, "Inertial Fusion Energy Power Plants Based on Laser or Ion Beams," Proceedings of The Ninth International Conference on Emerging Nuclear Energy Systems (ICENES-9), Tel-Aviv, Israel, June 28-July 2, 1998. Lawrence Livermore Laboratory, Livermore, CA, UCRL-JC-129241 (1998).

[2] M. MONSLER, J. MANISCALCO, J. BLINK, W. MEIER, and P. WALKER, "Electric power from laser fusion: the HYLIFE concept," in Proc. IECEC Conf., San Diego, California (1978); Lawrence Livermore National Laboratory, Livermore, CA, UCRL-1259.

[3] L. A. GLENN, "Transport processes in an inertial confinement fusion reactor," Nuc. Eng. Design 64, 375 (1981).

[4] J. A. BLINK, W. J. HOGAN, J. HOVINGH, W. R. MEIER, and J. H. PITTS, The High-Yield Lithium-Injection Fusion-Energy (HYLIFE). Reactor, Lawrence Livermore National Laboratory, Livermore, C^, UCID-53559 (1985).

[5] D. D.-M. Ho, J. D. Lindl, M. Tabak, "Radiation converter physics and a method for obtaining the upper limit for gain in heavy ion fusion," Nuclear Fusion 34 (1994) 1081-1095.

[6] R. W. Moir, "Heavy Ion Beam and Reactor Chamber Interface Design", Proceedings of the International Symposium on Heavy Ion Inertial Particle Accelerators, 37-38 459 (1992).

[7] R. W. Moir et al., "HYLIFE-II Progress Report," UCID-21816 (1991).

[8] R. W. Moir, R. L. Bieri, X. M. Chen, T. J. Dolan, M. A. Hoffman, P. A. House, R. L. Leber, J. D. Lee, Y. T. Lee, J. C. Liu, G. R. Longhurst, W. R. Meier, P. F. Peterson, R. W. Petzoldt, V. E. Schrock, M. T. Tobin, W. H. Williams, "HYLIFE-II: A Molten Salt Inertial Fusion Energy Power Plant Design-Final Report," Fusion Technology 25 (1994) 5-25.

[9] R. W. Moir, "The Logic Behind Thick, Liquid-Walled, Fusion Concepts," Nuclear Engineering and Design 29 (1995) 34-42.

[10] J. F. Latkowski and W. R. Meier, "Improved final focus shielding designs for modern heavy-ion fusion power plant designs," to be published in Nuclear Instruments and Methods in Physics Research A XXX (2000)XXX-YYY.

[11] D. A. Callahan-Miller, M. Tabak, "Increasing the coupling efficiency in a heavy ion, inertial confinement fusion target," Nuclear Fusion, 39 (1999) 1547-1556.

[12] P. A. House, "Beam line and first vessel wall shielding in HYLIFE-II," UCRL-UCID-136107, Lawrence Livermore National Laboratory, (1999). 
[13] P. A. House, "Focus magnet and vessel interface issues in HYLIFE-II," UCRL-UCID-to be assigned, Lawrence Livermore National Laboratory, (2000).

[14] P.F. Peterson, "Scaling and Design for Hydraulics Response in ThickLiquid Protected IFE Target Chambers," presented at First International Conference on Inertial Fusion Sciences and Applications, University . Bordeaux, France, September 12-17, 1999.

[15] Elwell, L. C., Collins, J. A., Yoda, M. and Abdel-Khalik, S. I., "Dynamics of obliquely oscillated turbulent free rectangular jets," American Physical Society Division of Fluid Dynamics Annual Meeting, New Orleans, LA (1999). Bulletin of the American Physical Society 44 (8), 154-155.

[16] A. I. Konkachbaev, N. B. Morley, K. Gulec, and T. Sketchley, "Stability and contraction of a rectangular liquid metal jet in a vacuum environment," Submitted to the $5^{\text {th }}$ International Symposium on Fusion Nuclear Technology, September 19-24, 1999, Rome, Italy. Lawrence Livermore Laboratory, Livermore, CA, UCRL-JC-132875 (June 18, 1999), submitted to Fusion Engineering and Design.

[17] R.Y. Bai and V.E. Schrock, "An Approximate method for analyzing transient condensation on spray in HYLIFE-II," Fus. Tech. 19 (1991) 732739.

[18] Jantzen, C; Lee, EP; Peterson, PF., "Parametric studies of ablation and venting from the central cavity of the HYLIFE-II reactor" FUSION TECHNOLOGY, 34 (1998)1047-1052.

[19] A. Molvik, private communications (Dec. 1999).

[20] W. R. Meier, "Osiris and Sombrero inertial fusion power plant designs-summary, conclusion, and recommendations," Fusion Engineering and Design, 25, (1994) 145-157.

[21] R. W. Moir, "Liquid walls for fusion reaction chambers," Lawrence Livermore Laboratory, Livermore, CA, UCRL-JC-135743 (Sept 16, 1999), submitted to Comments on Plasma Physics and Controlled Fusion.

[22] Per Peterson, UC Berkeley, private communications (8/31/99).

\section{Figure captions}

Fig. 1. The essential features resulting in $\sim 6 \mathrm{~Hz}$ pule rate from plant trade-off studies with driver energy are shown.

Fig. 2. Plant layout showing the driver, target and chamber. The use of liquid jets to protect the fusion chamber results in long lifetime, low cost, and low environmental impact.

Fig. 3. Chamber plan view. Note that liquid protects all the walls except up the beam lines. Venting can take place through the slots in the oscillating jets and around the jets. The circular cone encompassing the $19.1^{\circ}$ square array of beams is $\pm 22.4^{\circ}$.

Fig. 4. Chamber, side view.

Fig. 5. Cross flow shielding jets, which protect the beam ports. 
Fig. 6. Vertical jets for beam port protection.

Fig. 7. Density versus time showing condensation pumping and equilibrium vapor density. 